\title{
REGULARARTICLE
}

\section{ISOLATION AND MORPHOLOGICALLY IDENTIFICATION OF ASPERGILLUS FLAVUS INCIDENCES FROM MAIZE SEEDS IN ABUJA, NIGERIA}

Hajara Oyiza, Yusuf* ${ }^{1}$, Joshua Olu ${ }^{2}$, A. J.Alu ${ }^{3}$, T.S. Anjorin ${ }^{4}$

Address (es):

${ }^{1}$ Environmental Biotechnology and Bio conservation Department, National Biotechnology Development Agency, Along Musa Yar'adua Expressway, Airport Road, Lugbe -Abuja, PMB 5118, Wuse Zone 3, Abuja.

${ }^{2}$ Centre for Environmental Studies and Sustainable Development, Lagos State University, Ojo.

${ }^{3}$ Crop Science Laboratory, Faculty of Agriculture, University of Abuja.

${ }^{4}$ Department of Crop Protection, Faculty of Agriculture.

*Corresponding author : haj_yusuf@yahoo.ca

https://doi.org/10.36547/ft. 276

\section{ABSTRACT}

Food safety and security well implemented could help in making more crops available for consumption. Maize seed is a crop well known to be attacked by fungi such as Aspergillus flavus and reduce its nutrients. This study intends to isolate and morphologically identify the Aspergillus flavus from maize seeds from Abuja, Nigeria. The experimental design was complete randomized design involving untreated yellow (Y) and white (W) maize seeds from7 locations in Abuja, Nigeria. Pure culture of fungal isolate was prepared using Potato Dextrose Agar (PDA) and Sabouraud Dextrose Agar (SDA). Isolates obtained were characterized and identified on the basis of their colonial and morphological characteristics which include macroscopic and microscopic examinations. All maize seeds from the Abaji had no fungi incidences in both SDA and PDA, while all maize seeds from the experimental field show fungi incidences in both SDA and PDA. On SDA, the maize color yellow and white had F $(2,6)$ static values of 7.083 and 0.212 at $\mathrm{p}=0.129$ and 0.941 respectively. For the PDA, white maize seeds and yellow maize seeds from all the locations had $\mathrm{F}(2,6)$ static values of 0.377 and 0.521 at $\mathrm{p}=0.850$ and 0.773 . Aspergillus flavus was isolated in this study. The maize seeds from Kuje district and the experimental field 2 show a high incidence records. All growth of the Aspergillus in the two media used were not significant at $\mathrm{p}>0.05$.

Keywords: Maize seed, Aspergillus flavus, food safety, fungal incidences, Aflatoxin

\section{INTRODUCTION}

Fungi are known to cause deterioration and loss of nutrients in maize after insect (Debnath et al., 2012). The fungi genera Aspergillus, Bipolaris, Curvularia, Fusarium, and Penicillium which are well known fungi that attack seeds have been linked with maize seeds (Hussain et al., 2013). Aspergillus flavus is the most common member of the Aspergillus species in West African and the United States soils (Gachara $\boldsymbol{e t}$ al., 2018). Systemically, fungal attack on maize replete its viability, nutrient quality and quantity, seedling blight, failure in germination, subdued seedling and unappreciable crop performance (Enyiukwu and Ononuju, 2016). Aspergillus flavus is a saprophytic pathogen that thrives largely on many organic nutrient sources with sugars (Amaike and Keller, 2011). It is a fungus with wide economic impact which cut across been a pathogen of animals and insects, plants, cause of storage rots in large number of crops, production of highly regulated mycotoxin, aflatoxin B1(Klich, 2007). Its aflatoxin contaminants had been reported in some agricultural products (Perrone $\boldsymbol{e}$ al., 2014). A. flavus a well-known and cosmopolitan fungus could survive some series of environmental conditions (Abbas et al., 2009). They have the tendency to survive temperatures within $12^{\circ} \mathrm{C}$ to $48{ }^{\circ} \mathrm{C}$, an optimal growth temperature of $28{ }^{\circ} \mathrm{C}$ to $37{ }^{\circ} \mathrm{C}$ and a high humidity above $80 \%$ (Hell and Mutegi, 2011; Yu, 2012). As a storage mold on plants products, Maize seeds have been reported to be infected by A. flavus in the field prior to their harvest and in storage (Klueken et al., 2009).

Maize (Zea mays L.) a cereal crop belongs to the Poaceae family and it is rich in vitamins $\mathrm{A}, \mathrm{C}$ and $\mathrm{E}$, carbohydrate, protein, essential minerals, fibre and calories (Salako et al., 2019). Millions of maize about 8.63 million Metric Tons (MT) is produced annually in Nigeria (Sule $\boldsymbol{e t}$ al., 2014). It is a staple for over 1.2 million individuals in Africa and Americas (IITA, 2009; USDA, 2016). Maize is used as raw material for some industrial production, feed, fodder, and vegetable. It has been reported that poor storage condition, storage period, temperature, humidity levels and suitable climate could lead to infection caused by various storage fungi, such as Aspergillus species (Ezekiel et al. 2008)

This study intended to isolate and morphologically identify the Aspergillus flavus from maize seeds from Abuja, Nigeria.

\section{MATERIALS AND METHODS}

Study area

The maize seeds used in this study was obtained from seven (7) different locations across Abuja, Nigeria, Table 1 and Figure 1 illustrate their geographical location.

Table 1: Location where maize seeds were obtained with their geographical location

\begin{tabular}{|c|c|c|c|}
\hline Maize seed source & $\begin{array}{l}\text { Region in } \\
\text { Abuja }\end{array}$ & Abbreviation & $\begin{array}{l}\text { Latitude, } \\
\text { Longitude }\end{array}$ \\
\hline Bwari (BR) Market & $\begin{array}{l}\text { Abuja } \\
\text { North } \\
\text { (ABN) }\end{array}$ & $\mathrm{BR}$ & $9.3046 \mathrm{~N}, 7.3768 \mathrm{E}$ \\
\hline Goza (GZ) Market & $\begin{array}{l}\text { Abuja } \\
\text { North } \\
\text { (ABN) }\end{array}$ & GZ & $8.9307 \mathrm{~N}, 7.2994 \mathrm{E}$ \\
\hline $\begin{array}{l}\text { Gwagalada(GL) } \\
\text { Market }\end{array}$ & $\begin{array}{l}\text { Abuja } \\
\text { North } \\
\text { (ABN) }\end{array}$ & GL & $8.9308 \mathrm{~N}, 7.0969 \mathrm{E}$ \\
\hline $\begin{array}{l}\text { Experimental Field } \\
\text { UNIABUJA }\end{array}$ & - & $\mathrm{F}$ & $8.9807 \mathrm{~N}, 7.1805 \mathrm{E}$ \\
\hline Kuje Market & $\begin{array}{c}\text { Abuja } \\
\text { South-ABS }\end{array}$ & $\mathrm{KJ}$ & $8.8810 \mathrm{~N}, 7.2281 \mathrm{E}$ \\
\hline Kwali Market & $\begin{array}{c}\text { Abuja } \\
\text { South-ABS }\end{array}$ & KL & $8.8153 \mathrm{~N}, 7.0363 \mathrm{E}$ \\
\hline Abaji Market & $\begin{array}{c}\text { Abuja } \\
\text { South-ABS }\end{array}$ & $\mathrm{AB}$ & $8.5082 \mathrm{~N}, 7.0348 \mathrm{E}$ \\
\hline
\end{tabular}

Seed collections

Two different color of maize seeds were obtained from six different markets across Abuja and experimental field, University of Abuja (UNIABUJA). Distribution of the location where the maize seeds were obtained is as illustrated in Fig. 1. 


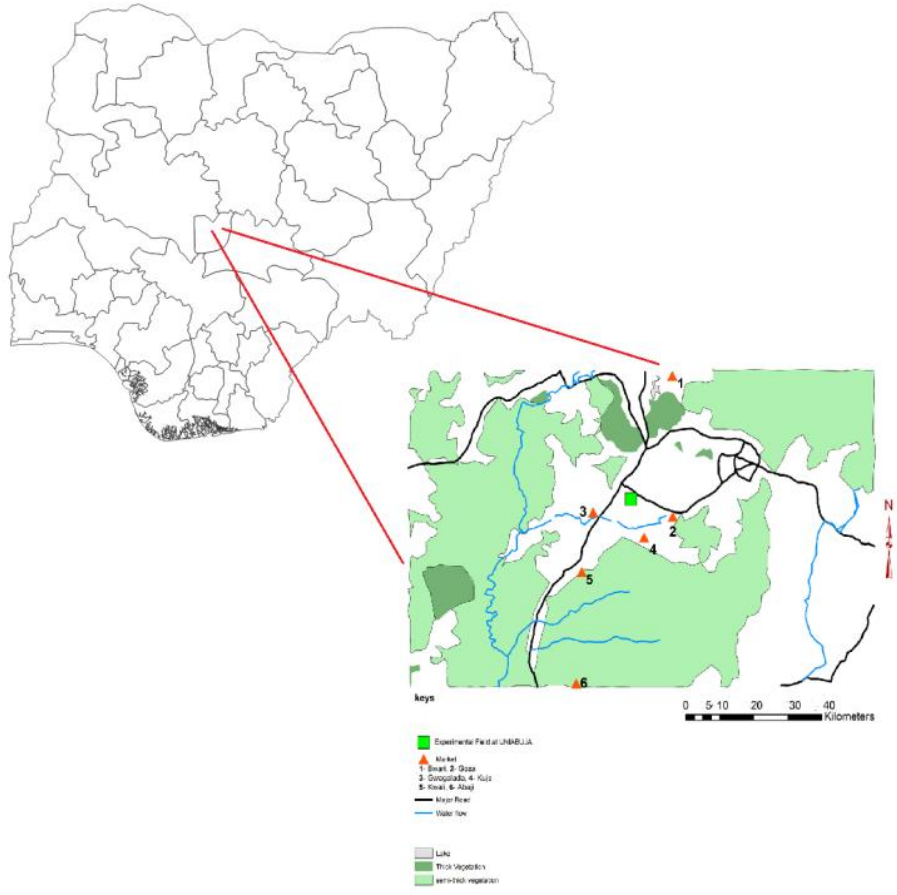

Figure 1: Map showing where the maize seeds were obtained in Abuja, Nigeria

Preparation and sterilization of media

Sabouraud Dextrose Agar (SDA)

SDA was used in this study and prepared according to the manufacturer's instructions thus, $65 \mathrm{~g}$ of SDA is dissolved in $1000 \mathrm{ml}$ of sterile water and then sterilized (autoclaved) at $121{ }^{\circ} \mathrm{C}$ and pressure of $15 \mathrm{pa}$ for 15 minutes

\section{Potato Dextrose Agar}

PDA was also used in this study and prepared according to the manufacturer's instructions thus; $39 \mathrm{~g}$ of PDA powder was added to 1 liter of distilled water and boil while mixing to dissolve completely. The sterilization was done at $121^{\circ} \mathrm{C}$ for 15 minutes using the autoclave. The sterilized prepared media was dispensed aseptically into petri dishes.

Preparation of pure culture of fungal isolate

The young fungal colony were aseptically picked up and transferred to fresh sterile SDA and PDA plates to obtain pure culture. The pure cultures on SDA and PDA plates were grown at $25 \pm 2{ }^{\circ} \mathrm{C}$ for 7 days and kept under $4{ }^{\circ} \mathrm{C}$ in a refrigerator. The isolates were subculture to obtain young cultures for further studies (Klich, 2000).

\section{Identification of the fungal isolate}

Cultural identification

Twelve isolates obtained from subculture were characterized and identified on the basis of their colonial and morphological characteristics which include macroscopic and microscopic examinations. Among the characteristics used were colonial characteristics such as size, surface, appearance, texture, and reversed pigmentation of the colonies of sporing structures. Appropriate references were done by using mycological identification keys and taxonomic description (Harrigan and McCance, 2006)

\section{Morphological Characterization of Aspergillus flavus}

Morphological attributes as described by Klich (2002) and Clayton in Thathana et al., (2017) were then utilized for further verification the isolates. Attributes such as colony color, colony growth, colony texture exudation which could be classified as macroscopic characteristics were studied. For microscopic analysis, attributes such as vesicles, asconidiophores, phialides, matulae and conidia were observed under the microscopic analysis of the isolate. Riddell's classic slide culture method (Thathana et al., 2017) and a method described by Diba et al., (2007) were used for the cultivation of the isolation the microscopic slides. Motic BA210 Basic Biological Light Microscope (Motic Instruments Inc., Richmond, BC, Canada) were used to examine the prepared slides using the immersion oil (100x) objective lens.

Incidence of fungi

Incidences of fungal infection on each sample were calculated by using the following formula:
In $(\%)=($ Number of infected seeds $) /($ Total number of seeds $) \times 100$.

\section{RESULTS AND DISCUSSION}

The incidence of the fungi was calculated and stated as indicated in Table 1. In this study, from findings stated in Table 2, there was more fungi incidences with the potato dextrose agar (PDA) compared to the Sabouraud Dextrose Agar (SDA).

Table 2: Mean Incidence of Fungi on yellow and white maize seeds collected from field and farmer store across Abuja

\begin{tabular}{llll}
\hline No. & Sample code & \multicolumn{2}{l}{ Incidence \% } \\
& & SDA & PDA \\
\hline 1 & FY & 14 & 11.23 \\
2 & FW & 2.9 & 6.3 \\
3 & GLW & 0.0 & 0.0 \\
4 & GL Y & 10.2 & 6.5 \\
5 & BR W & 0.0 & 0.0 \\
6 & BR Y & 0.0 & 8.0 \\
7 & GZ W & 0.0 & 16.0 \\
8 & GZ Y & 0.0 & 3.3 \\
9 & KJ W & 0.0 & 0.0 \\
10 & KJ Y & 30.4 & 14.4 \\
11 & AB W & 0.0 & 0.0 \\
12 & AB Y & 0.0 & 0.0 \\
13 & KL W & 2.9 & 0.0 \\
14 & KL Y & 5.8 & 0.0 \\
\hline
\end{tabular}

Legend: F-Field, Y-yellow, W-white, GL- Gwagwalada, KL- Kwali, KJ- Kuje, $\mathrm{BR}$-Bwari, GZ-Goza and AB-Abaji

All maize seeds from the Abaji ( $\mathrm{AB} Y$ and $\mathrm{AB} W$ ) had no fungi incidences in both SDA and PDA, while all maize seeds from the experimental field (F Y and F W) show fungi incidences in both SDA and PDA. The yellow maize seed overall show more fungi incidence than the white maize seeds. On SDA, from Table 3 the maize color yellow and white had $F(2,6)$ static values of 7.083 and 0.212 at $p=0.129$ and 0.941 respectively.

Table 3: Analysis of variance of the maize types from the different location on the two media

\begin{tabular}{cccc}
\hline Media type & Maize colour & $\mathrm{F}(2,6)$ & Significance \\
\hline SDA & White & 0.212 & 0.941 \\
& Yellow & 7.083 & 0.129 \\
PDA & White & 0.521 & 0.773 \\
& Yellow & 0.377 & 0.850 \\
\hline
\end{tabular}

For the PDA, white maize seeds and yellow maize seeds from all the locations had $F(2,6)$ static values of 0.377 and 0.521 at $p=0.850$ and 0.773 . The study by Sowley $\boldsymbol{e}$ t al., (2018) also reported a non-significant fungal incidence occurrence from maize samples.

\section{Phenotypic Characterization of the Aspergillus flavus Isolates}

Macroscopic Characteristics of the Isolates on PDA

The colony characteristics of the isolates are shown in Fig. 2 at the inception, the isolates were seen to have mycelia white color.

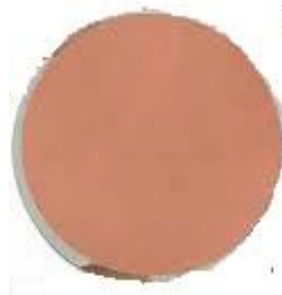

Control

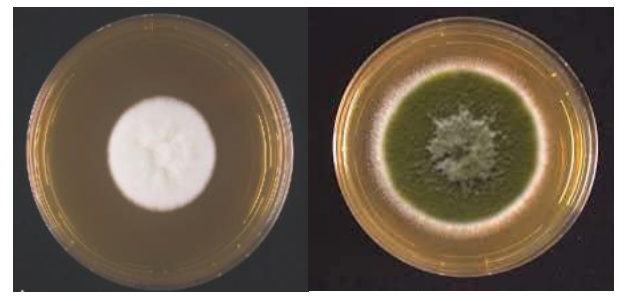

Aspergillus flavus
Figure 2: Colony morphology of Aspergillus flavus isolates on PDA

The isolates after three days were seen to produce olive and dark green conidia, which happen to be the predominant appearance of the colony. They look raised in the center but their edges appear to be flat and plain with wrinkled in pattern like a cerebri. Droplets of liquid that is brown or uncolored were produced by the isolates. Sclerotia that were deep brown in coloration were produced in the 
isolates. The colonies were encircled by a white border, and the colony diameter ranged between 65 and $75 \mathrm{~mm}$. The undersides of the colonies were slightly pale Macroscopic Characteristics of the Isolates on SDA

The attributes of the isolated colony are shown in Fig. 3. On the SDA the isolate colony were at the inception white with a velvety soft surface. After four days of growth, a floccose was seen at the center with a raise.

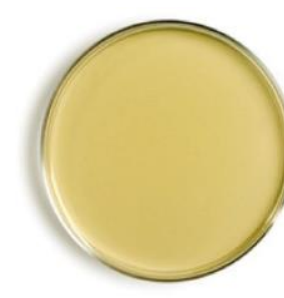

Control

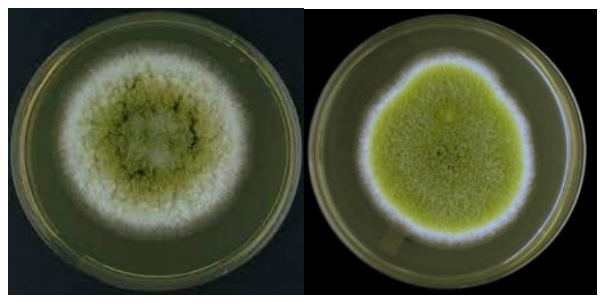

Aspergillus flavus
Figure 3: Colony morphology of Aspergillus flavus isolates on SDA

Yellowish-green and olive conidia were produced by the colony during sporulation. The whole surface of the colony was covered by conidia the edges, where border whitish in color were seen. On the sixth day of incubation, the produced sclerotia which were white initially became deep brown. No droplet of liquid known as exudates was produced.

\section{Microscopic Characteristics of the A. flavus Isolates}

The isolates were examined to ascertain their definitive identification, the microscopic attributes (conidiophores, conidia, metulae, phialides and vesicles) (Fig. 4). The conidiophores appeared uncolored, thick walled, roughened and vesicles bearing. Their diameter ranged between 800 and $1200 \mu \mathrm{m}$. Some isolates exhibit vesicles that were subglobose and globose in others with difference in diameter, ranging between 1800 and $2000 \mu \mathrm{m}$. There were uniseriate or biseriate or both kind of cells. The phialides were situated on the metuale with the biseriate cells, but attached to the vesicle, in uniseriate cells. The vesicles were covered with the metulae and radiated in all directions from the vesicles. Globose with thin wall with 250 and $450 \mu \mathrm{m}$ range in diameter made up the conidia.

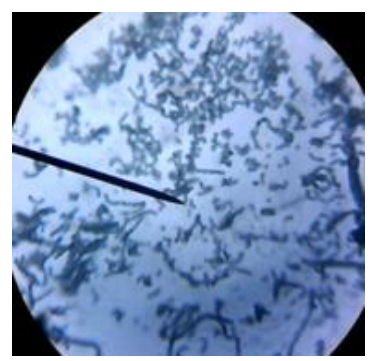

Figure 4: Aspergillus flavus sporex 100

According to Da Gloria (2011), both field and storage fungus contamination incidences in maize may vary among farms or producers in the same regions. This study share this view, for instance all the maize from Abaji-AB (yellow and white) show no fungal incidence in both PDA and SDA medium as illustrated in Table 2. While the case of Gwagalada-GL and Kuje-KJ yellow side there was fungal incidence in both PDA and SDA. The environmental situations and conditions could be a major determinant in the varying occurrences of A. flavus in the various districts of Abuja indicated in this study. Warm climate play a significant role in a huge chance of infection by aflatoxin producing fungal in some regions and this infection occurs only when there is drought with increase in temperature (Cotty and Jaime-Garcia, 2007).

Diba et al., (2007) examined the morphological characteristics of Aspergillus species from some specimens and they indicated that Aspergillus growth and conidia production maybe fasten if potato dextrose, malt extract, or likewise sporulation agars are used in growing them. This study used potato dextrose ag ar which from Table 2 show more incidence than SDA. Morphological methods as used in this study, had been reported to be used in identifying Aspergillus species from the soils in Fars and Kerman provinces of Iran (Mohammadi et al., 2009) and Larkana district in Pakistan (Afzal et al., 2013).

\section{CONCLUSION}

Aspergillus flavus was isolated in this study and the maize seeds from Abuja South Kuje district and the experimental field shows a high incidence records. All growth of the Aspergillus in the media were not significant at $p>0.05$. The maize seeds that recorded more incidences of Aspergillus flavus could be infected by higher levels of aflatoxins that cause some ill-health issue to humans, animals and plants. It will be wise then for fungus to be fight to its minimum in crops.

Acknowledgment: The authors wish to express gratitude to the staff of Crop Science Laboratory, Faculty of Agriculture, University of Abuja for their support during the course of this research.

\section{REFERENCES}

Abbas, H.; Wilkinson, J.; Zablotowicz, R.; Accinelli, C.; Abel, C.; Bruns, H. and Weaver, M. (2009). Ecology of Aspergillus flavus, regulation of aflatoxin production, and management strategies to reduce aflatoxin contamination of corn. Toxin Rev., 28, 142-153.https://doi.org/10.1080/15569540903081590

Afzal, H., Shazad, S., Qamar, S. and Nisa, U. (2013). Morphological identification of Aspergillus species from the soil of Larkana District (Sindh, Pakistan). Asian J. Agric. Biotechnol., 1, 105-117.

Amaike, S. and Keller, N.P. (2011). Aspergillus flavus. Annu. Rev. Phytopathol., 49, 107-133. https://doi.org/10.1146/annurev-phyto-072910-095221

Cotty, P.J. and Jaime-Garcia, R. (2007). Influences of climate on aflatoxinproducing fungi and aflatoxin contamination. Int. J. Food Microbiol., 119, 109115. https://doi.org/10.1016/j.ijfoodmicro.2007.07.060

Da Gloria, M.E. (2011). Aflatoxin contamination distribution among grains and nuts. In: Torres-Pacheco, I., Ed.; Aflatoxins-Detection, Measurement and Control, (pp75-90) InTech: Rijeka, Croatia.

Debnath M. Sultana A. and Rashid A.Q.M.B. (2012). Effects of seed-borne fung i on the germinating seeds and their biocontrol in maize. J. Environ. Sci. Nat. Res. 5(1), 117-120. https://doi.org/10.3329/jesnr.v5i1.11564

Diba, K.; Rezaie, S.; Mahmoudi, M.; Kordbacheh, P. and Diba, C.K. (2007). Identification of Aspergillus species usingmorphological characteristics. Pak. J. Med. Sci., 23, 867-872.

Enyiukwu, D.N. and Ononuju CC (2016). Comparative priming effects of phytochemicals from Alchornea cordifolia and Piper guineense on cowpea (Vigna unguiculata L. Walp.) J.Plant Pest Sci. 3(1), 001-004

Ezekiel, C. N., Odebode, A. C. and Fapohunda, S. O. (2008). Zearalenone Production by naturally occurring Fusarium sp. on maize, wheat and soybeans from Nigeria. Journal of Biology and Environment Science, 6, 77-82.

Gachara, G.W., Nyamache, A.K., Harvey, J., Gnonlonfn. G.J.B. and Wainaina J . (2018). Genetic diversity of Aspergillus flavus and occurrence of aflatoxin contamination in stored maize across three agro-ecological zones in Kenya. Agric\& Food Secur. 7, 52. https://doi.org/10.1186/s40066-018-0202-4

Harrigan, W.F. and McCance, M.E. (2006). Laboratory Methods in Food and Dairy Microbiology, Academic Press, London.

Hell, K. and Mutegi, C. (2011). Aflatoxin control and prevention strategies in key crops of Sub-Saharan Africa. Afr. J. Microbiol. Res., 5, 459-466.

Hussain N, Hussain A, Ishtaq M, Azam S, and Hussain T (2013). Pathogenicity of two seedborne fungi commonly involved in maize seeds of eight districts of Azad Jammu and Kashmir, Pakistan. Afr. J. Biotechnol. 12(12), 1363-1370. https://doi.org/10.5897/AJB12.454.

International Institute for Tropical Agriculture (IITA) (2009). Maize Crop. www.iita.org/crops/maize.

Klich, M.A. (2000). Identification of common Aspergillus species. (pp.116) Centraal bureau voor Shimmel cultures Utrecht. The Netherlands

Klich, M.A. (2002). Identification of Common Aspergillus Species; (pp. 426432) Centraal bureau voor Schimmel cultures: Utrecht, The Netherlands

Klich, M.A. (2007). Aspergillus flavus: the major producer of aflatoxin. Molecular plant pathology 8(6), 713-722. https://doi.org/10.1111/J.13643703.2007.00436.X

Klueken, A.; Borgemeister, C. and Hau, B. (2009). Field release of a nontoxigenic Aspergillus flavus L strain in Central Benin. J. Plant Dis. Prot., 116, 17-22. https://doi.org/10.1007/BF03356281

Mohammadi, A.H., Banihashemi, Z. and Haghdel, M. (2009). Identification and prevalence of Aspergillus species in soils of fars and Kerman provinces of Iran and evaluation of their aflatoxin production. Rostanilha, 10, 23. https://www.sid.ir/FileServer/JE/80220093201.pdf

Perrone, G., Gallo, A. and Logrieco, A.F. (2014). Biodiversity of Aspergillus section Flaviin Europe in relation to the management of aflatoxin risk. Frontiers in Microbiology 5, 1-5. https://doi.org/10.3389/fmicb.2014.00377

Salako, E.A., Anjorin, T.S. and Machunga-Mambula, S. S (2019). Assessment of the efficacy of garlic (Allium sativumL.) extract for the control of Aspergillus flavus and other fungi on maize seeds in North central, Nigeria. Journal of Agricultural Research and Natural Resources 3(2), 056-075.

Sowley, E.N.K, Kankam, F. and Tawiah, E. (2018). Comparative Study on the Incidence of Aspergillus flavus in Farmer's Field and Stored Maize (Zea mays) 
Seed in Northern Region of Ghana. Asian Plant Research Journal 1(2), 1-7. https://doi.org/10.9734/apri/2018/v1i226269

Sule EI, Umoh VJ, Whong CMZ Adbulahi IO and Alabi O (2014). Chemical and Nutritional value of maize and maize products obtained from Kaduna State Nigeria. Afr. J. Food Sci. Technol. 5(4), 100-104. http://dx.doi.org/10.14303/ajfst.2014.029

Thathana, M.G.,Murage, H., Abia, A.L.K. and Pillay, M. (2017). Morphological Characterization and Determination of Aflatoxin-Production Potentials of Aspergillus flavus Isolated from Maize and Soil in Kenya. Agriculture 7, 80. https://doi.org/10.3390/agriculture 7100080

United State Department of Agriculture (USDA) (2016). United State Department of Agriculture (2007). Nutrient content information for yellow maize. USDA. www.usda.org/ nutrient - info-maize Accessed April 21, 2016.

$\mathrm{Yu}$, J. (2012). Current understanding on aflatoxin biosynthesis and future perspective in reducing aflatoxin contamination. Toxins, 4, 10241057. https://doi.org/10.3390/toxins 4111024 